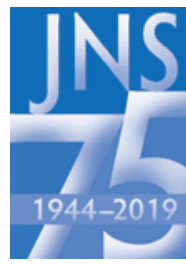

\title{
Fetal surgery for spina bifida
}

\author{
JNSPG 75th Anniversary Invited Review Article \\ Michael C. Dewan, MD, MSCI, and John C. Wellons III, MD, MSPH
}

Department of Neurosurgery, Division of Pediatric Neurosurgery, Monroe Carell Jr. Children's Hospital at Vanderbilt, Vanderbilt University Medical Center, Nashville, Tennessee

\begin{abstract}
The two-hit hypothesis of neural injury in the wake of open neural tube defects suggests an opportunity for preservation of function and potential reversibility of early morphological changes in the fetus diagnosed with myelomeningocele. The Management of Myelomeningocele Study (MOMS) demonstrated reduced need for shunting and improved neurological function in patients treated in utero relative to postnatally, thereby offering level 1 evidence supporting fetal repair. Subsequent studies have offered additional information about urological, orthopedic, radiological, and maternal factors surrounding fetal repair. The quest for robust long-term neurocognitive and motor function data is underway and poised to shape the future of fetal repair. In addition, technical innovations such as fetoscopic surgery aim to minimize maternal morbidity while conferring the beneficial effects observed with open intrauterine intervention.
\end{abstract}

https://thejns.org/doi/abs/10.3171/2019.4.PEDS18383

KEYWORDS fetal; fetoscopic; intrauterine; myelomeningocele; spina bifida; congenital

$\mathrm{M}$ YELOMENINGOCELE (MM) represents the most common congenital malformation affecting the nervous system, resulting from incomplete closure of the posterior neuropore during primary neurulation. It is observed in approximately 30 of every 100,000 live births in North America, ${ }^{22,46}$ and considerably higher in many low-resourced populations, including those of sub-Saharan Africa and parts of Southeast Asia. ${ }^{13}$ Dietary supplementation with folate, an important substrate for neurulation, remains the most important public health intervention curbing the prevalence of MM in many parts of the world. ${ }^{36}$

\section{Rationale for Prenatal Repair}

Traditionally, an open neural defect is closed in the days following childbirth. By establishing a skin-covered layer above the defect, open postnatal repair mitigates the risk of meningitis and serves to achieve a suitable cosmetic result. Moreover, creating a protective plane between the neural tissue and the external environment theoretically alleviates further neurological damage to the more rostral nerve roots and spinal cord.

The widespread use of advanced prenatal ultrasonog- raphy, offering a detailed survey of neural development in utero, suggests progressive neurological deterioration in the fetus with MM. The rationale for prenatal repair begins with the so-called "two-hit hypothesis" assigned to MM, borne from the observation that neurological sequelae advance during gestation. ${ }^{22}$ An initial and immediate neurological injury occurs at the time of primary neurulation failure. Then, contact of the neural tissue with neurotoxic intrauterine contents imparts additional damage. ${ }^{40}$ In addition, the Chiari malformation type II (CM-II) is believed to result from the caudal suction effect of the CSF pocket within the spinal defect. While the primary embryological insult is irreversible, it follows that intrauterine repair (IUR) might prevent the subsequent neurological damage, and therefore offer the child improved neurological function and morbidity avoidance. ${ }^{16}$

\section{Early Animal and Human Studies}

Some of the earliest animal models were designed to demonstrate the second component of the two-hit theory: neurological deterioration upon direct exposure to the amniotic cavity. In murine and porcine models, surgically created dysraphism defects were either closed intrauter-

ABBREVIATIONS CHOP = Children's Hospital of Philadelphia; CM-II = Chiari malformation type II; CPC = choroid plexus cauterization; ETV = endoscopic third ventriculostomy; fMMR = fetal MM repair; IUR = intrauterine repair; MM = myelomeningocele; MOMS = Management of Myelomeningocele Study; PROM = premature rupture of membranes; TCS $=$ tethered cord syndrome; $\mathrm{VP}=$ ventriculoperitoneal.

SUBMITTED March 30, 2019. ACCEPTED April 16, 2019.

INCLUDE WHEN CITING DOI: 10.3171/2019.4.PEDS18383. 
inely or kept open until birth. ${ }^{16,17}$ Relative to controls, the cohort undergoing surgical repair demonstrated improved neurological function and less physical deformity. In a primate model, Michejda showed that fetal repair could yield excellent neurological results, relative to untreated monkeys who suffered paraplegia, incontinence, and sensory loss. ${ }^{30}$ Perhaps the most accurate model reflective of human MM pathophysiology is the ovine model developed by Meuli et al. and later modified by other pioneers in the field of fetal surgery. ${ }^{29}$ The sheep that underwent in utero repair exhibited superior neurological function and restoration of normal hindbrain architecture. ${ }^{4,34}$

Exploration of fetal MM repair (fMMR) in humans began via an endoscopic approach in the early 1990s in several centers in the US and Europe. ${ }^{8,15,24}$ Dismal results in these early series shifted the field toward open techniques, such that by the end of the millennium, several institutions produced more encouraging data for fMMR. Investigators at Vanderbilt University and Children's Hospital of Philadelphia demonstrated that patients treated via open fMMR displayed less hindbrain herniation and a normalization of CSF dynamics, which resulted in a reduction of postnatal shunting procedures. ${ }^{1,721,41}$ While these early data suggested a possible benefit to the fetus, major questions remained, including those regarding perioperative fetal health, maternal safety, and implications of fMMR on subsequent pregnancies, among others.

\section{The Management of Myelomeningocele Study \\ Methods}

Built upon findings from the aforementioned animal and preclinical human studies, the Management of Myelomeningocele Study (MOMS) sought to prove the efficacy and safety of IUR with level 1 evidence. This was a prospective, randomized clinical trial comparing prenatal versus postnatal closure at three geographically disparate centers: Vanderbilt University Medical Center, the University of California, San Francisco, and Children's Hospital of Philadelphia (CHOP). ${ }^{2}$ Upon prenatal diagnosis of MM, mothers were referred to one of these three centers wherein strict inclusion and exclusion criteria were applied. During the trial, there was a moratorium on nontrial centers performing IUR. Candidates included singleton pregnancies between 19 and 26 weeks of gestation, without unrelated fetal anomalies or an abnormal placenta. Mothers were excluded if they were morbidly obese (BMI $>35 \mathrm{~kg} /$ $\mathrm{m}^{2}$ ) or had other comorbidities deemed potentially harmful to the fetus (HIV-positive, poorly controlled hypertension), lacked the requisite psychosocial support, or were unable to relocate to one of the trial centers.

Mothers randomized to the treatment arm underwent intrauterine closure before 26 weeks' gestation and remained near the fetal surgery center until 37 weeks, when the child was delivered by cesarean section. Mothers in the postnatal arm sought routine prenatal care at home and then returned to the fetal surgery center at 37 weeks for a scheduled cesarean section. The same neurosurgical team then performed the postnatal MM repair within 48 hours of delivery. Children were followed up at 12 and 30 months of age with physical and neurological examinations and development assessments. The first primary outcome, at 12 months, was a composite of death or the need for a CSF shunt. Both adjudicated and actual proportions were reported. The second primary outcome was mental development and motor function at 30 months. Secondary outcomes included maternal surgical and pregnancy-related complications, as well as child functional disability and presence and degree of CM-II findings.

\section{Technique}

The MM closure technique was standardized across centers, and at the time represented the customary intrauterine closure method. After creation of an adequately sized hysterotomy by the fetal surgery team, the fetus was administered an intramuscular injection of fentanyl and vecuronium. The neurosurgeon sharply incised the neural placode from the surrounding tissue to allow the neural contents to descend into the canal. Next, the dura was incised circumferentially and reflected over the defect and closed with fine running suture. In the case of insufficient dura, a synthetic substitute was onlaid over the defect. Finally, the skin was mobilized and closed using running monofilament, with relaxing flank incisions employed only as needed (Fig. 1).

\section{Results: Primary and Secondary Outcomes}

MOMS enrollment was terminated early due to efficacy in the prenatal arm, after 187 of the originally planned 200 patients were randomized. Both primary outcomes were positively influenced. The actual rate of shunt placement was $40 \%$ in the prenatal surgery group relative to $82 \%$ in the postnatal surgery group $(\mathrm{p}<0.001)$. The adjudicated rate was $68 \%$ and $98 \%$, respectively $(\mathrm{p}<0.001)$. Radiographic findings at the 12-month follow-up were also more favorable in the prenatal surgery group, showing lesser degrees of hindbrain herniation, brainstem kinking, and syringomyelia observed relative to the postnatal group. In addition, the composite outcome of the Bayley Mental Development Index and motor level improvement at 30 months were better in the prenatal surgery group $(\mathrm{p}$ $=0.007)$. It is important to note that the statistical difference in this outcome is driven by the motor improvement and not the Bayley Mental Development Index scores. Patients treated prenatally were more likely to have a level of function two or more levels better than expected according to anatomical level ( $32 \%$ vs $12 \%, \mathrm{p}=0.005)$, despite having more severe lesions than their postnatally treated counterparts.

\section{Drawbacks}

The benefits observed must be weighed against several risks associated with fetal surgery. The prenatal group was delivered significantly earlier (34.1 vs 37.3 weeks, $\mathrm{p}<$ $0.001)$, and severe prematurity ( $<30$ weeks) was observed in $13 \%$ of prenatal patients compared with no patients in the postnatal cohort. Chorionic membrane separation, premature rupture of membranes (PROM), spontaneous membrane rupture, spontaneous preterm labor, and oligohydramnios all occurred with greater frequency in 

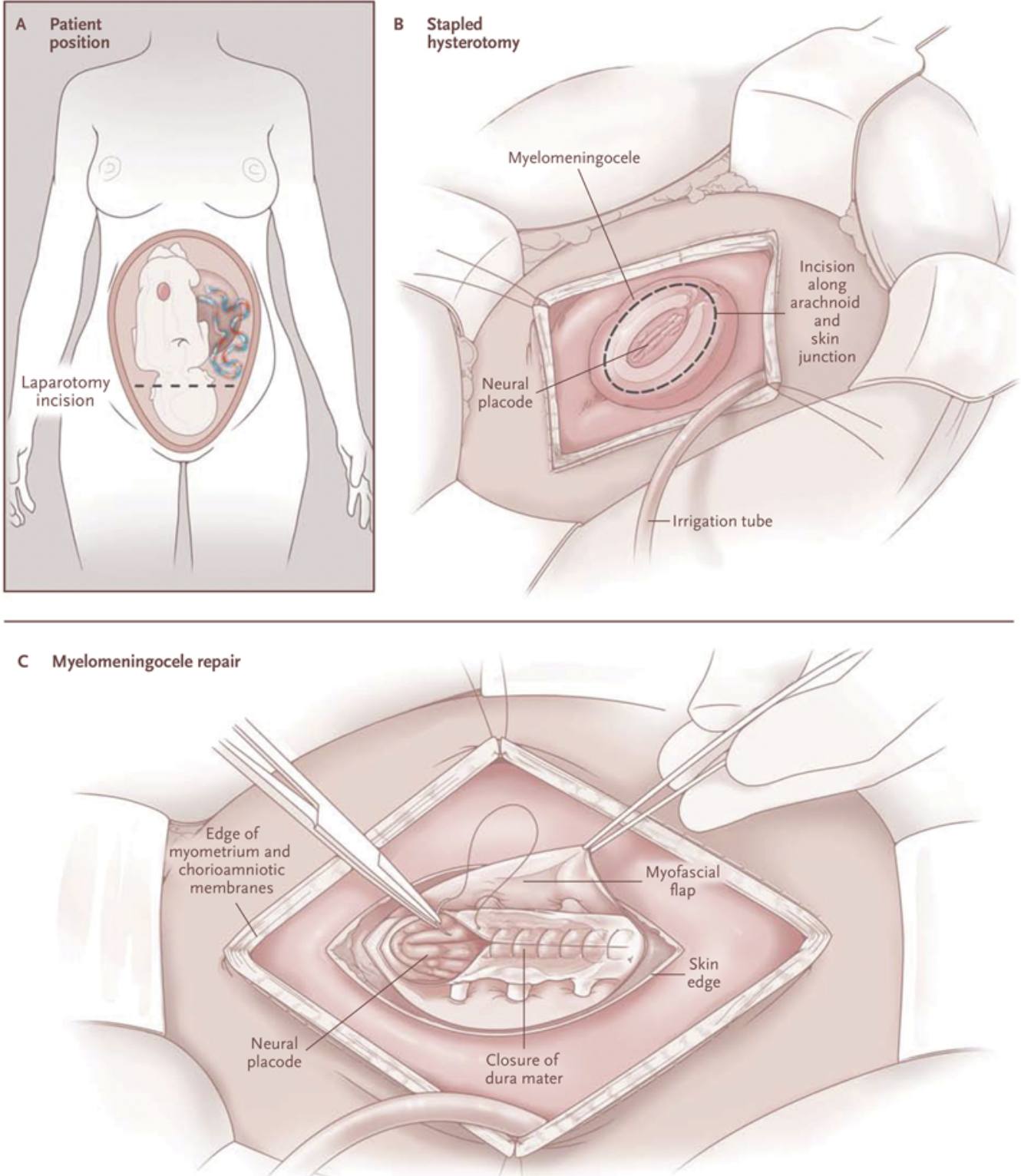

FIG. 1. Exposure of the uterus and fetus $(\mathbf{A})$ is depicted as originally described in the MOMS trial. The transitional zone between the arachnoid centrally and the skin laterally is incised $(\mathbf{B})$, permitting descent of the neural tissue. When possible, the dura was incised circumferentially and reflected over the defect and closed with fine running suture (C). From Adzick NS, Thom EA, Spong CY, Brock JW III, Burrows PK, Johnson MP, et al: A randomized trial of prenatal versus postnatal repair of myelomeningocele. N Engl J Med 364:993-1004, 2011. Copyright @ 2019, Massachusetts Medical Society. Reprinted with permission from Massachusetts Medical Society. Figure is available in color online only.

the prenatal arm. Maternal risks were also greater following fetal surgery, i.e., pulmonary edema and the need for blood transfusion were more common among women in the prenatal cohort. Lastly, all mothers are counseled that future pregnancies must be delivered by cesarean section to avoid the risk of uterine dehiscence and rupture.

\section{After MOMS \\ MOMS Cohort Subanalyses}

Since publication of the early-terminated trial results, several analyses have been conducted on the full MOMS cohort to ascertain the influence of prenatal repair on CSF circulatory, functional, urological, and maternal outcomes. Tulipan et al. updated the results using the entire randomized cohort of 183 patients and found that the primary outcome (fetal/infant death, CSF shunting, or meeting prespecified criteria for a shunt) occurred in $73 \%$ of infants in the prenatal group relative to $98 \%$ in the postnatal group $(\mathrm{p}<0.001) .{ }^{42}$ Actual rates of shunt placement, however, more closely reflected the MOMS findings: $44 \%$ versus $84 \%$ in the two groups. The difference between these sets of figures appeared to hinge on the portion of the shunting criteria detailing overt signs and symptoms 
of hydrocephalus, i.e., a bulging fontanelle, split sutures, or sunsetting eyes. When these were not present, the predetermined criteria were less likely to be followed in the decision to place a CSF shunt. Another important finding was that among the prenatal cohort, fetal ventricle size at prenatal screening, as measured by atrial diameter, correlated with the need for postnatal shunt insertion. Twenty percent of those with a ventricle size $<10 \mathrm{~mm}$ required a shunt, relative to $79 \%$ of those with a ventricle size $>$ $15 \mathrm{~mm}$. Among the postnatal group such a dramatic difference was not observed, as more than $80 \%$ of patients required a shunt irrespective of ventricle size. Finally, a ventriculoperitoneal (VP) shunt placed in a patient with prenatal repair appeared to be more durable, requiring a revision at less than half the rate as one placed in a postnatal patient. The authors concluded that caution should be taken when advising the family of a patient with enlarged ventricles $(>15 \mathrm{~mm}$ ), as a primary benefit to IUR (shunt freedom) appears to disappear in this subpopulation.

Because the trial was stopped early for efficacy, the MOMS flagship publication only included 30-month outcomes for 134 of the 183 randomized mother-child dyads. In a second analysis of the MOMS cohort for 30-month outcomes by Farmer et al. in 2018, inspection of the full cohort of patients supported the original observations: prenatal repair improves motor development and reduces the rate of permanent CSF diversion. ${ }^{14}$ No relationship was drawn between postnatal motor function and prenatal ventricular size. Therefore, the authors concluded that outcomes related to CSF diversion should be treated separately from those of distal neurological function during prenatal counseling for potential intrauterine surgery. ${ }^{14}$

Additional topic-specific subanalyses of the MOMS data in 2015 and 2016 revealed that the rate of clean intermittent catheterization was not different between the two groups; however, among the prenatal cohort there was less bladder trabeculation and open bladder neck. ${ }^{5}$ Obstetric complications associated with prenatal surgery were confirmed on close inspection of the entire MOMS cohort. Early gestational age at surgery and chorioamniotic membrane separation were associated with spontaneous membrane rupture. In addition, oligohydramnios was found to be a risk factor for preterm delivery. ${ }^{20}$

\section{Post-MOMS Clinical Studies}

Since the landmark MOMS publication, several groups have reported their post-MOMS patient outcomes, providing insight on what fetal surgery for MMC is like for offtrial patients. The first such publication was from Vanderbilt in 2014 comparing 43 patients who underwent fMMR at Vanderbilt to the MOMS prenatal cohort. ${ }^{3}$ The goal of this study was to evaluate a modification to the uterine opening in an effort to reduce amniotic membrane separation and other related maternal complications. Improved maternal outcomes were observed relative to the original trial cohort. The incidence of PROM was reduced by half ( $22 \%$ vs $46 \%, p=0.011)$ and chorioamnion separation was eliminated altogether ( $0 \%$ vs $26 \%$, p < 0.001$)$. Adjustments in the surgical technique also correlated with prolonged gestation. Nearly twice as many babies were born at term (39\% vs $21 \%, \mathrm{p}=0.03)$, and only $4 \%$ were born earlier than 30 weeks compared with $13 \%$ of the MOMS cohort $(\mathrm{p}=0.084)$. Forty-one percent of patients required VP shunting, similar to the original trial $(40 \%))^{2,3}$

The following year, the largest cohort of patients postMOMS was reported from CHOP describing 100 consecutive fMMRs and their postoperative course..$^{32}$ Among the 587 mothers referred to this high-volume center between 2011 and 2014, 101 (17\%) were taken to the operating room for IUR. The most common reasons for exclusion were the discovery of additional anomalies on imaging, preexisting maternal medical condition, and declining the on-site prenatal appointment (11\% each). Maternal BMI $>35 \mathrm{~kg} / \mathrm{m}^{2}$ was uncommon (2\%), and termination of pregnancy occurred in a minority of patients referred for fMMR (7\%). The gestational age at the time of surgery was 23.3 weeks, or 1 week earlier than the MOMS cohort. The average gestational age at delivery was 34.3 weeks and 54\% of babies were born at 35 weeks or later, both figures essentially matching those in the MOMS trial patients. Maternal complications were slightly lower than in MOMS, suggesting a learning benefit as well as improvements in the surgical proceedings. Relative to MOMS, the CHOP post-MOMS patients were less likely to experience membrane separation ( $23 \%$ vs $26 \%$ ), PROM (32\% vs $46 \%$ ), oligohydramnios (6\% vs $21 \%$ ), and maternal transfusion (3\% vs 9\%). Preterm labor was equivalent between groups (37\% vs 38\%). Importantly, there were 6 prenatal deaths $(6 \%)$ in the post-MOMS group compared to the 2 (3\%) in the MOMS trial. The overall rate of shunting was not reported in this cohort, although $71 \%$ of patients with imaging demonstrated no evidence of hindbrain herniation postnatally. Fifty-five percent of patients undergoing a postnatal physical evaluation were assigned a functional level that was one level or more better than that determined by prerepair anatomical level. ${ }^{32}$

\section{Inclusion Cysts and Spinal Cord Tethering}

As with postnatal MMC closure, inclusion cysts and spinal cord tethering are important complications that can arise following fetal repair. ${ }^{10,28}$ While the incidence of symptomatic tethered cord syndrome (TCS) following postnatal repair is approximately $10 \%-13 \%,,^{18,39}$ as many as a third (33\%) of fMMR patients may experience this condition..$^{11}$ It is notable that inclusion cysts (such as dermoids and epidermoids) are found in the majority of fMMR patients who present with signs and symptoms of TCS. ${ }^{11}$ Unresected epithelial tissue from the transitional zone surrounding the placode may be the source of these inclusion cysts. ${ }^{27}$ Accordingly, the technical challenge of removing all such epithelia during intrauterine surgery relative to postnatal repair may form the basis for the increased incidence. Whether multilayer closure, dural or dermal substitute grafting, suture type, and/or endoscopic approach influence the rate of inclusion cyst formation or tethering remains an active area of study. It is generally believed among fetal surgeons that the incidence of inclusion cysts decreases with experience over time, due to both the experience of individual surgeons becoming more accustomed to the procedure and the growing field performing open fMMR. 


\section{Quality of Child Life and Long-Term Development}

Until recently, little has been understood about longterm outcomes following fMMR. As pre-MOMS patients have begun to approach late childhood and early adolescence, higher-level neurofunctional assessments can be administered. Among 42 children treated at CHOP preMOMS, Danzer and colleagues found that the vast majority (nearly $80 \%$ ) were community ambulators at a median follow-up of 10 years, while $14 \%$ were wheelchair bound. ${ }^{11}$ Normal bladder function was present in $25 \%$ of patients. The need for shunting correlated with worse behavioral adaptive skills, while the need for tethered cord release surgery was associated with deterioration of motor skills. Importantly, early neurofunctional and ambulatory status predicted long-term neurocognitive scores and motor function. ${ }^{11}$

Our center recently administered quality of life assessments to our pre-MOMS fMMR cohort, all between 14 and 19 years of age, and compared them to a control sample of postnatally treated patients of the same epoch. ${ }^{33}$ Fewer patients in the prenatal group required future neurosurgical procedures (VP shunting, tethered cord release, etc.) than their postnatal counterparts. Additionally, patients who underwent fetal repair scored higher on the psychosocial health assessment and total quality of life assessment than the postnatal controls. Interestingly, physical health scores were similar between the two groups..$^{33}$

The MOMS II study is designed to address these questions with greater rigor. Funded by the Eunice Kennedy Shriver National Institute of Child Health and Human Development, this study evaluates children from the original MOMS cohort now aged 5 to 8 years old (NIH NICHD grant no. 5U01HD068541-05). Adaptive behavior, cognitive functioning, motor level and function, and urological health are all assessed, along with brain morphology and connectivity using high-resolution imaging. In addition to child health, quality of life, maternal health, and family impact are all measured in this study, which is expected to be published in the near future.

It is important to emphasize the ongoing work by the North American Fetal Therapy Network (NAFTNet), a voluntary consortium currently consisting of 31 centers that specialize in complex disorders of the fetus. This group studies multiple problems of the developing fetus, not limited to spina bifida. However, a primary focus is a prospective database involving fMMR across North America among member institutions. With the ever-increasing numbers of fetal surgery centers, it is critical that prospective data be collected so that best practice can be determined and promulgated throughout the field.

\section{Shifting Attitudes of Hydrocephalus Treatment}

Since MOMS, there has been a growing cultural pivot in attitudes regarding shunt placement, in both parents and pediatric neurosurgeons. It may be argued that this change was brought on by MOMS itself, as parent and surgeon alike were forced to decide what constituted the need for shunt placement and, therefore, failure of the primary outcome of MOMS. This is made clear by the discrepancy in those meeting shunt placement criteria and those actually receiving a shunt. As noted previously in the Tulipan et al. follow-up study on the MOMS cohort, when the shunt criteria were not followed, it was because of the lack of physical signs of hydrocephalus such as a bulging fontanelle, split suture, or sunsetting eyes. ${ }^{42}$ Indeed, surgeons in the Hydrocephalus Clinical Research Network found these signs critical when making decisions in the treatment of very low-birth-weight infants with intraventricular hemorrhage of prematurity. ${ }^{38,44,45}$

Shortly after this relaxed shunt placement criteria came the increasing popularity of endoscopic third ventriculostomy (ETV) and choroid plexus cauterization (CPC) for the treatment of hydrocephalus presenting for various reasons in infancy. A significant additional cultural shift began specific to the perception of appropriate ventricular size for intervention. When should we treat patients with ventriculomegaly? When should we take them back for a repeat ETV/CPC? Is the true measure of size change best performed via z-score, frontooccipital horn ratio, or brain volume? ${ }^{12,26}$ This change in willingness to accept larger ventricular size also has made an impact on not only initial treatment for hydrocephalus, but also which of the two options are considered. Often parents are more likely to accept a procedure that is not "the shunt."

A cynic would say that the benefit of the reduced incidence of CSF diversion provided by fMMR in MOMS is mitigated by these complex cultural changes over the ensuing decade. However, the authors choose to believe that the implementation of fetal surgery for spina bifida, at least as specific to symptomatic hydrocephalus alone, is one part of an overall treatment approach that began with folic acid fortification, and continues with fetal surgery in appropriately identified patients, the incorporation of a more reserved approach in the decision to treat ventriculomegaly, and involving the initial use of ETV/CPC where appropriate.

\section{Emerging Surgical Techniques and Future Perspectives}

Beyond optimizing surgical techniques to reduce uterine-related complications, improvements in the spinal defect closure technique have also been described since the MOMS trial. Frequently, fetal dura is too thin and tenuous to serve as the only reliable barrier beneath an often-stretched skin layer. Using needlepoint electrocautery, Moldenhauer and Adzick at CHOP now create two membrane-lined myofascial flaps beyond the dura, and suture them together in the midline for a thicker, tensionfree spinal canal covering. ${ }^{19,31}$ As the number of centers performing fMMR has grown, so have the variations on closing the defect. Specifically, there are several different schools of thought on dural primary closure versus onlay, muscle and fascia mobilization, and management of a defect too wide for primary closure. At this time, there is no evidence that any one way is superior to the other.

\section{Fetal MM Closure as Performed at the Fetal Center at Vanderbilt}

The patient is admitted 1 day prior to surgery, when preoperative laboratory samples are drawn and an ultrasound examination is conducted to demonstrate estimated 


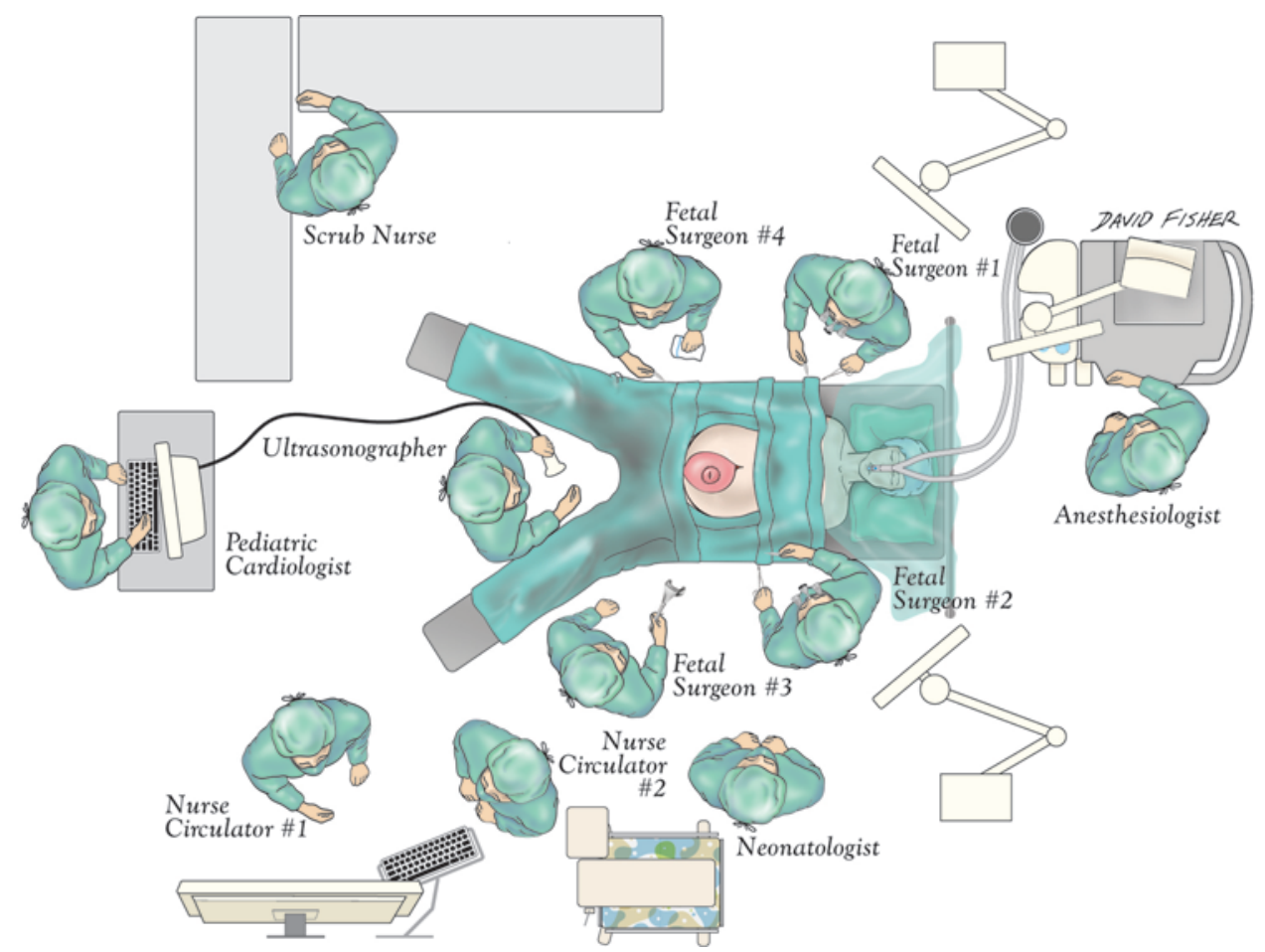

FIG. 2. Operating room orientation. The multidisciplinary team-including maternal fetal medicine, pediatric neurosurgery, neonatology, pediatric cardiology, plastic surgery, anesthesia, operating room technicians, nurses, and sonographers-is essential for safe and efficient MM IUR. Copyright David Fisher, Fisher Illustration and Design. Published with permission. Figure is available in color online only.

fetal weight and position. The anesthesia and obstetric teams evaluate and give final clearance for surgery. The fetal surgical team consists of maternal fetal medicine, pediatric neurosurgery, neonatology, pediatric cardiology, plastic surgery, anesthesia, operating room technicians, nurses, and sonographers (Fig. 2).

After a combination of general and epidural anesthesia is administered, the uterus is exposed via a vertical incision from the pubis to just above the umbilicus. The fetus and placenta are located via ultrasound and a 6- to $8-\mathrm{cm}$ hysterotomy incision is created, based on avoiding the placenta and proximity of the MM sac. Meticulous care is given to suturing the uterine lining up to the opening within the uterus and minimizing direct trauma to these membranes during the intrauterine portion of the procedure. ${ }^{3}$ The fetus is administered fentanyl and vecuronium and undergoes continuous echocardiographic monitoring throughout the procedure (Fig. 3).

Under loupe magnification, the placode is sharply incised, allowing the neural contents to descend within the canal (Fig. 4). Most commonly, a synthetic dural substitute is onlaid and the focus moves to skin closure. Occasionally if the dura is judged to be substantial enough for a watertight closure, it is closed as a separate layer. The skin is mobilized and if there is not a sufficient amount of tissue for an adequate closure, an early decision is made for at least a single relaxing flank incision in order to create a bipedicled skin flap. This then allows a tensionless primary closure with a running absorbable monofilament directly over the defect. Using the same suture type, an acellular dermal allograft is then sewn into the flank incisions in a running fashion. After delivery, it is noted that this tissue is often either incorporated into the surrounding skin or quickly sloughed off to reveal well-healing granulation tissue beneath. The uterus is then closed in layers followed by abdominal fascia and skin closure. The patient recovers in the obstetric postsurgical unit and a cesarean section is scheduled for 37 weeks.

\section{Fetoscopic Surgery}

With advancements in minimally invasive techniques and endoscopic capabilities, fetoscopic repair of MMC has begun to garner attention. In theory, the mother stands to benefit from the avoidance of a large abdominal incision and minimization of uterine scarring. Moreover, if fetoscopy can mitigate membrane rupture rates, the fetus may sustain a longer gestation period. Endoscopy for fetal dysraphism is not new, having been pioneered at Vanderbilt first in animal models in 1993. ${ }^{9}$ Indeed, the first fMMR surgery in a human was performed endoscopically-not open -in 1994 by means of a maternal graft onlay. ${ }^{6}$

However, initial results in humans were disappointing. Among the first 4 patients treated endoscopically by Bruner and colleagues, 2 died perinatally and the other 2 required a postnatal wound revision and shunt. ${ }^{6}$ In a report by Farmer et al. from 2003, 2 of 3 patients died following endoscopic repair, leading the authors to suggest that minimally invasive fMMR would be unethical until improved upon and validated in clinical trials. ${ }^{15}$ 

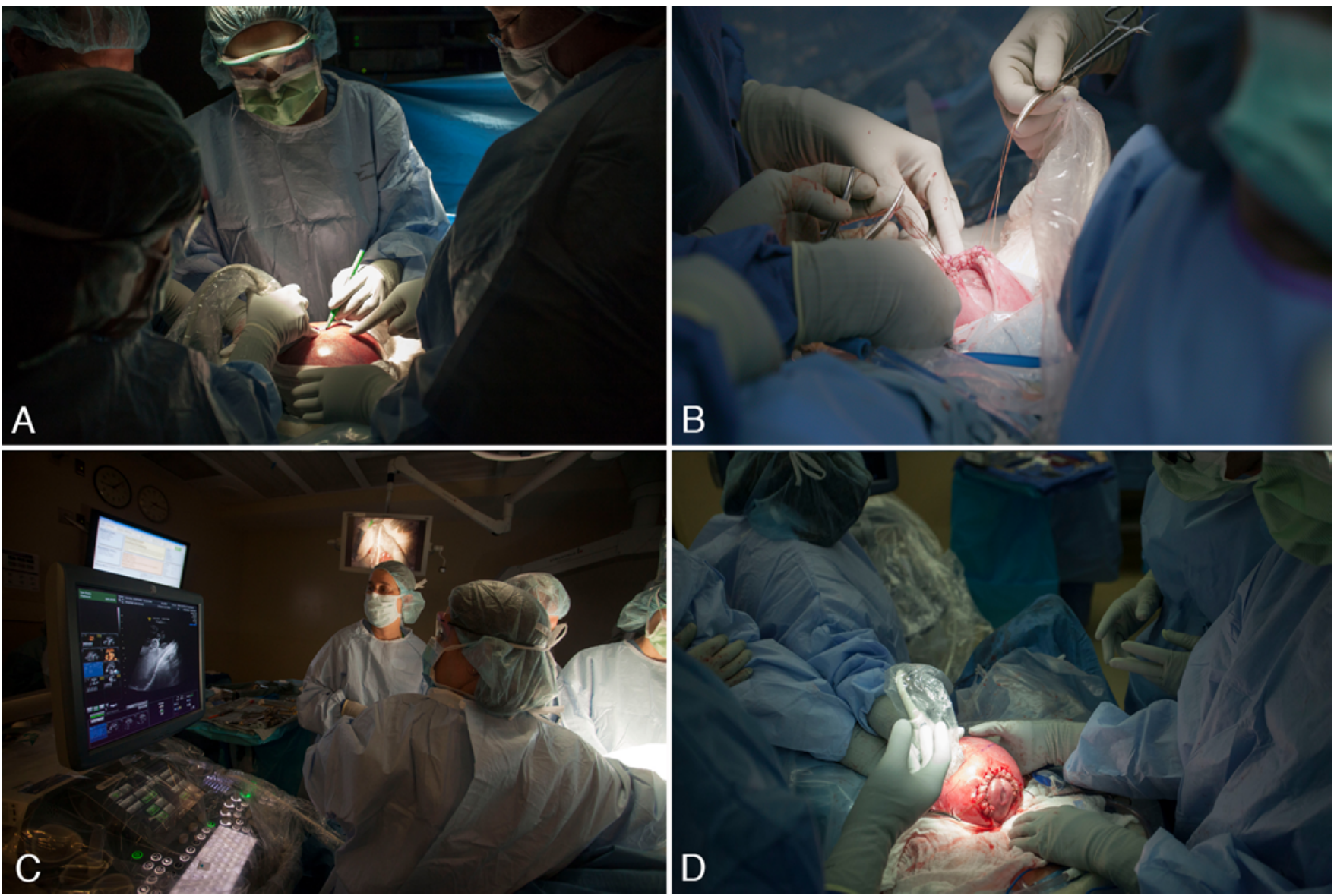

FIG. 3. Fetal exposure. Under sonographic guidance the hysterotomy is planned to optimize exposure of the spinal defect while protecting the placenta, umbilical cord, and other relevant fetal anatomy $(\mathbf{A})$. The uterus is entered with electrocautery, the membrane is opened, and full-thickness running locked sutures secure the membrane to the uterine wall (B). Fetal cardiac monitoring is used throughout the case, with continuous communication between pediatric cardiology and anesthesia ( $C$ and $\mathbf{D})$. Figure is available in color online only.

As a result, fetoscopic approaches were largely abandoned until the MOMS results were published, and innovative methods were refocused on minimizing maternal morbidity and optimizing future pregnancies. Earlier, Kohl and colleagues had described a percutaneous fetal procedure first in sheep ${ }^{23}$ and then in humans ${ }^{24}$ in which a synthetic patch is placed over the spinal defect, thus protecting the neural elements from caustic intraamniotic fluids. However, this technique mandated formal skin closure in the postnatal setting. By 2012, this group had improved their technique to include suturing of an absorbable patch over the defect followed by skin approximation with synthetic graft supplementation. ${ }^{25}$ In their series of 19 patients, neurological function (motor/sensory level, muscle density) was improved relative to postnatally treated controls. However, 3 (16\%) suffered fetal demise, 3 (16\%) had iatrogenic hemorrhage and procedural termination, and the same obstetric complications (PROM, chorioamnionitis, oligohydramnios) observed in open fetal repair were observed here. ${ }^{43}$ In 2016, Pedreira et al. published their series of 10 patients treated with endoscopic placement of a biocellulose patch followed by single-layer skin closure. While feasibility was demonstrated, the overall results were not favorable: 2 patients (20\%) died, PROM occurred in all cases, and gestational age at birth was nearly 2 weeks earlier than those of the MOMS prenatal cohort (32.4 vs 34.1 weeks). ${ }^{35}$ Onlay patches with variable degrees and methods of securement, while technically simpler than primary dural closure, appeared to result in less favorable wound results and persistent maternal morbidity; the socalled "patch-and-glue" technique lost traction.

More recently, Whitehead and colleagues at Texas Children's Hospital have pioneered an endoscopic multilayer closure designed to retain the maternal advantages of minimal uterine manipulation offered by endoscopy while also minimizing CSF and wound complications associated with nonsutured graft closures. ${ }^{37}$ In this two-port technique, a patch graft is placed over the circumferentially incised and descended placode. A dura/fascial flap is created on either side of the spinal canal and, along with the overlying skin, reapproximated with interrupted sutures. In a preliminary report of the first 12 cases using this closure technique, $70 \%$ of infants were born vaginally and there were no cases of uterine dehiscence. Twenty-five percent experienced PROM and were born less than 37 weeks' gestational age. Surgical time, however, was lengthy (mean 

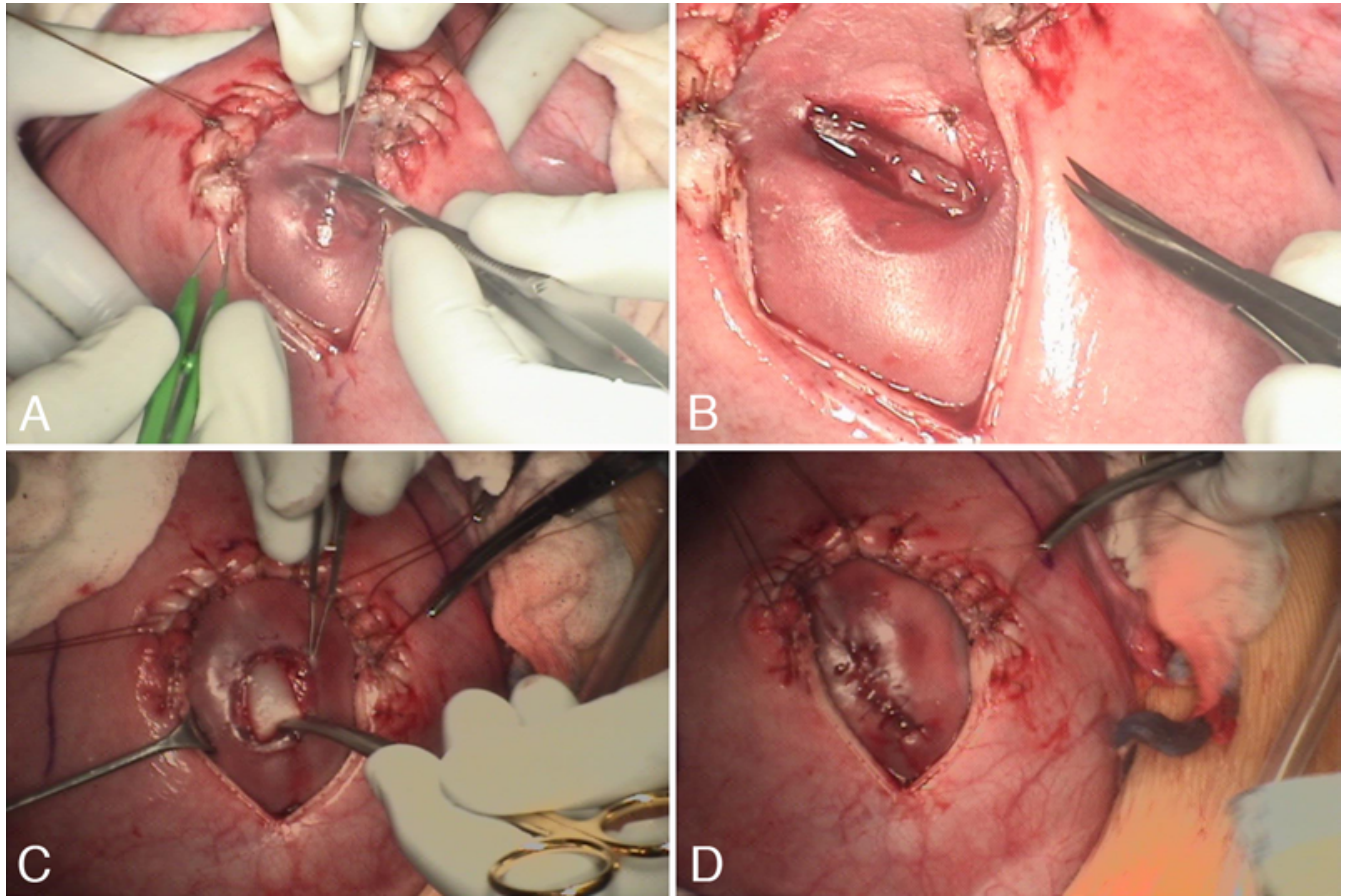

FIG. 4. MM closure. The zona epitheliosa, or transition zone, is incised sharply (A) to allow the placode to descend within the canal (B). Surrounding dura is then mobilized and reapproximated in the midline and closed with a running suture. If insufficient or patulous dura precludes a watertight closure, a synthetic dural substitute graft is onlaid over the placode and canal defect (C). Finally, the fetal skin overlying the lumbodorsal fascia is mobilized and closed with a running monofilament suture (D). If the skin cannot be approximated, relaxing flank incisions are made. Figure is available in color online only.

243 minutes), most of which was required for neural tube defect closure (mean 141 minutes). In this minimally invasive, multilayer technique, there were no CSF leaks or need for wound revisions, while $90 \%$ saw reversal of hindbrain herniation and the vast majority $(80 \%)$ demonstrated a functional level improvement. ${ }^{37}$ While early results are intriguing, validation from larger cohorts across multiple centers is needed before the fetoscopic method can be considered among the standards for fMMR.

\section{Further Technical Innovation}

It would be remiss to not speculate on continued technical innovations for in utero surgery application. Currently, spina bifida is the only nonlethal disease for which fetal intervention is offered. As applicability increases, there will be more opportunity for instrument and platform adaptation. For example, the use of endoscopy is purported to enable mothers to return to a vaginal delivery for the subsequent child with a decreased risk of uterine rupture or fetal demise. The pivot to a focus on vaginal delivery and successful subsequent pregnancies reflects the positive outcomes for children not only in hydrocephalus and neurological function, but also in reducing the incidence of preterm delivery. The initial fetoscopic work had challenging outcomes and there were issues with wound healing, resulting in returns to the operating room after delivery as well as fetal demise. This improved over time, with experience. There are limitations of the endoscopic technique, specifically the lack of instrument wrist articulation and dexterity at the point of interface with the patient. The surgical robot, used for years by general and urological surgeons for intracavitary procedures, is designed to overcome these types of issues. Several centers have begun to experiment with robotic intrauterine surgery simulations, including Vanderbilt. It is the opinion of the authors that this will be the most likely next step in fetal surgery innovation.

\section{Conclusions}

Intrauterine surgery for spina bifida has been a quartercentury journey. The early pioneers of the procedure deserve great credit for overcoming both the procedural challenges and the naysayers who felt the risk outweighed the benefit. However, without the early criticism and doubt, it is unlikely a trial such as MOMS would have commenced. What started with early investigations prompting an NIHfunded multicenter trial has now grown to include over 15 centers across North America and the world that perform fMMR. Each year, more centers are offering fMMR. Recent growth of the entire specialty of fetal medicine dedicated to caring for women with fetal neurological anomalies is largely due to this relatively rapid procedural climatization.

There is unlikely to be another study on this topic of the magnitude of MOMS. Whether one argues that the shunting culture of today or advent of ETV/CPC mitigates the findings of MOMS in any way, or that the indications for fetal surgery for spina bifida should be expanded, it is difficult to argue its impact on our field. The original MOMS cohort will continue to be studied on a longer-term basis 
for the primary and secondary outcomes, as well as tethering, urinary function, and quality of life. As pediatric neurosurgeons, crucial to the overall effort, we must critically examine the modifications to the original procedure in order to define and disseminate best practices. Then we must begin that process again. As more centers gain expertise, opportunities for innovation should increase, not wane. The field should not be content with the outcomes of today, however improved they are compared with the early days of fMMR. Our goal for the patient receiving a prenatal diagnosis of spina bifida should be the elimination of hydrocephalus, normalization of neurological function, term delivery for the infant, and the ability of the mother to return to a normal risk for subsequent pregnancy.

\section{References}

1. Adzick NS, Sutton LN, Crombleholme TM, Flake AW: Successful fetal surgery for spina bifida. Lancet 352:1675-1676, 1998

2. Adzick NS, Thom EA, Spong CY, Brock JW III, Burrows PK, Johnson MP, et al: A randomized trial of prenatal versus postnatal repair of myelomeningocele. N Engl J Med 364:993-1004, 2011

3. Bennett KA, Carroll MA, Shannon CN, Braun SA, Dabrowiak ME, Crum AK, et al: Reducing perinatal complications and preterm delivery for patients undergoing in utero closure of fetal myelomeningocele: further modifications to the multidisciplinary surgical technique. J Neurosurg Pediatr 14:108-114, 2014

4. Bouchard S, Davey MG, Rintoul NE, Walsh DS, Rorke LB, Adzick NS: Correction of hindbrain herniation and anatomy of the vermis after in utero repair of myelomeningocele in sheep. J Pediatr Surg 38:451-458, 2003

5. Brock JW III, Carr MC, Adzick NS, Burrows PK, Thomas JC, Thom EA, et al: Bladder function after fetal surgery for myelomeningocele. Pediatrics 136:e906-e913, 2015

6. Bruner JP, Richards WO, Tulipan NB, Arney TL: Endoscopic coverage of fetal myelomeningocele in utero. Am J Obstet Gynecol 180:153-158, 1999

7. Bruner JP, Tulipan N, Paschall RL, Boehm FH, Walsh WF, Silva SR, et al: Fetal surgery for myelomeningocele and the incidence of shunt-dependent hydrocephalus. JAMA 282:1819-1825, 1999

8. Bruner JP, Tulipan NE, Richards WO: Endoscopic coverage of fetal open myelomeningocele in utero. Am J Obstet Gynecol 176:256-257, 1997

9. Copeland ML, Bruner JP, Richards WO, Sundell HW, Tulipan NB: A model for in utero endoscopic treatment of myelomeningocele. Neurosurgery 33:542-545, 1993

10. Danzer E, Adzick NS, Rintoul NE, Zarnow DM, Schwartz ES, Melchionni J, et al: Intradural inclusion cysts following in utero closure of myelomeningocele: clinical implications and follow-up findings. J Neurosurg Pediatr 2:406-413, 2008

11. Danzer E, Thomas NH, Thomas A, Friedman KB, Gerdes M, Koh J, et al: Long-term neurofunctional outcome, executive functioning, and behavioral adaptive skills following fetal myelomeningocele surgery. Am J Obstet Gynecol 214:269. e1-269.e8, 2016

12. Dewan MC, Lim J, Gannon SR, Heaner D, Davis MC, Vaughn $\mathrm{B}$, et al: Comparison of hydrocephalus metrics between infants successfully treated with endoscopic third ventriculostomy with choroid plexus cauterization and those treated with a ventriculoperitoneal shunt: a multicenter matched-cohort analysis. J Neurosurg Pediatr 21:339-345, 2018

13. Dewan MC, Rattani A, Mekary R, Glancz LJ, Yunusa I, Baticulon RE, et al: Global hydrocephalus epidemiology and incidence: systematic review and meta-analysis. J Neurosurg 130:1065-1079, 2019

14. Farmer DL, Thom EA, Brock JW III, Burrows PK, Johnson MP, Howell LJ, et al: The Management of Myelomeningocele Study: full cohort 30-month pediatric outcomes. Am J Obstet Gynecol 218:256.e1-256.e13, 2018

15. Farmer DL, von Koch CS, Peacock WJ, Danielpour M, Gupta $\mathrm{N}$, Lee $\mathrm{H}$, et al: In utero repair of myelomeningocele: experimental pathophysiology, initial clinical experience, and outcomes. Arch Surg 138:872-878, 2003

16. Heffez DS, Aryanpur J, Hutchins GM, Freeman JM: The paralysis associated with myelomeningocele: clinical and experimental data implicating a preventable spinal cord injury. Neurosurgery 26:987-992, 1990

17. Heffez DS, Aryanpur J, Rotellini NA, Hutchins GM, Freeman JM: Intrauterine repair of experimental surgically created dysraphism. Neurosurgery 32:1005-1010, 1993

18. Herman JM, McLone DG, Storrs BB, Dauser RC: Analysis of 153 patients with myelomeningocele or spinal lipoma reoperated upon for a tethered cord. Presentation, management and outcome. Pediatr Neurosurg 19:243-249, 1993

19. Heuer GG, Adzick NS, Sutton LN: Fetal myelomeningocele closure: technical considerations. Fetal Diagn Ther 37:166171,2015

20. Johnson MP, Bennett KA, Rand L, Burrows PK, Thom EA, Howell LJ, et al: The Management of Myelomeningocele Study: obstetrical outcomes and risk factors for obstetrical complications following prenatal surgery. Am J Obstet Gynecol 215:778.e1-778.e9, 2016

21. Johnson MP, Sutton LN, Rintoul N, Crombleholme TM, Flake AW, Howell LJ, et al: Fetal myelomeningocele repair: short-term clinical outcomes. Am J Obstet Gynecol 189:482-487, 2003

22. Joyeux L, Danzer E, Flake AW, Deprest J: Fetal surgery for spina bifida aperta. Arch Dis Child Fetal Neonatal Ed 103:F589-F595, 2018

23. Kohl T, Hartlage MG, Kiehitz D, Westphal M, Buller T, Achenbach S, et al: Percutaneous fetoscopic patch coverage of experimental lumbosacral full-thickness skin lesions in sheep. Surg Endosc 17:1218-1223, 2003

24. Kohl T, Hering R, Heep A, Schaller C, Meyer B, Greive C, et al: Percutaneous fetoscopic patch coverage of spina bifida aperta in the human-early clinical experience and potential. Fetal Diagn Ther 21:185-193, 2006

25. Kohl T, Tchatcheva K, Merz W, Wartenberg HC, Heep A, Müller A, et al: Percutaneous fetoscopic patch closure of human spina bifida aperta: advances in fetal surgical techniques may obviate the need for early postnatal neurosurgical intervention. Surg Endosc 23:890-895, 2009

26. Mandell JG, Kulkarni AV, Warf BC, Schiff SJ: Volumetric brain analysis in neurosurgery: Part 2. Brain and CSF volumes discriminate neurocognitive outcomes in hydrocephalus. J Neurosurg Pediatr 15:125-132, 2015

27. Martínez-Lage JF, Ruiz-Espejo Vilar A, Almagro MJ, Sánchez del Rincón I, Ros de San Pedro J, Felipe-Murcia M, et al: [Spinal cord tethering in myelomeningocele and lipomeningocele patients: the second operation.] Neurocirugia (Astur) 18:312-319, 2007 (Spanish)

28. Mazzola CA, Albright AL, Sutton LN, Tuite GF, Hamilton RL, Pollack IF: Dermoid inclusion cysts and early spinal cord tethering after fetal surgery for myelomeningocele. N Engl J Med 347:256-259, 2002

29. Meuli M, Meuli-Simmen C, Hutchins GM, Yingling CD, Hoffman KM, Harrison MR, et al: In utero surgery rescues neurological function at birth in sheep with spina bifida. Nat Med 1:342-347, 1995

30. Michejda M: Intrauterine treatment of spina bifida: primate model. Z Kinderchir 39:259-261, 1984

31. Moldenhauer JS, Adzick NS: Fetal surgery for myelomenin- 
gocele: After the Management of Myelomeningocele Study (MOMS). Semin Fetal Neonatal Med 22:360-366, 2017

32. Moldenhauer JS, Soni S, Rintoul NE, Spinner SS, Khalek N, Martinez-Poyer J, et al: Fetal myelomeningocele repair: the post-MOMS experience at the Children's Hospital of Philadelphia. Fetal Diagn Ther 37:235-240, 2015

33. Mummareddy N, Dewan MC, Huang A, Basem J, Bennett $\mathrm{KA}$, Shannon CN, et al: Intrauterine closure of myelomeningocele is associated with superior long-term quality of life than postnatal closure: a single-center study. J Neurosurg Pediatr [epub ahead of print May 17, 2019. DOI: 10.3171/2019.4.PEDS18770]

34. Paek BW, Farmer DL, Wilkinson CC, Albanese CT, Peacock W, Harrison MR, et al: Hindbrain herniation develops in surgically created myelomeningocele but is absent after repair in fetal lambs. Am J Obstet Gynecol 183:1119-1123, 2000

35. Pedreira DAL, Zanon N, Nishikuni K, Moreira de Sá RA, Acacio GL, Chmait RH, et al: Endoscopic surgery for the antenatal treatment of myelomeningocele: the CECAM trial. Am J Obstet Gynecol 214:111.e1-111.e11, 2016

36. MRC Vitamin Study Research Group: Prevention of neural tube defects: results of the Medical Research Council Vitamin Study. Lancet 338:131-137, 1991

37. Ravindra VM, Belfort M, Sanz Cortes M, Espinoza J, Shamshirsaz A, Nassr A, et al: Multi-layer fetoscopic repair of open neural tube defects: early perinatal outcomes, presented at the 47th Annual Meeting of the AANS/CNS Section on Pediatriac Neurological Surgery, December 7, 2018 (Poster) (https://www.aans.org/Online-Program/Eposter?ev entid $=48899 \&$ itemid=SSI $\&$ propid=43552) $[$ Accessed April 23, 2019]

38. Riva-Cambrin J, Shannon CN, Holubkov R, Whitehead WE, Kulkarni AV, Drake J, et al: Center effect and other factors influencing temporization and shunting of cerebrospinal fluid in preterm infants with intraventricular hemorrhage. J Neurosurg Pediatr 9:473-481, 2012

39. Steinbok P, Irvine B, Cochrane DD, Irwin BJ: Long-term outcome and complications of children born with meningomyelocele. Childs Nerv Syst 8:92-96, 1992

40. Stiefel D, Copp AJ, Meuli M: Fetal spina bifida in a mouse model: loss of neural function in utero. J Neurosurg 106 (3 Suppl):213-221, 2007

41. Sutton LN, Adzick NS, Bilaniuk LT, Johnson MP, Crombleholme TM, Flake AW: Improvement in hindbrain herniation demonstrated by serial fetal magnetic resonance imag- ing following fetal surgery for myelomeningocele. JAMA 282:1826-1831, 1999

42. Tulipan N, Wellons JC III, Thom EA, Gupta N, Sutton LN, Burrows PK, et al: Prenatal surgery for myelomeningocele and the need for cerebrospinal fluid shunt placement. J Neurosurg Pediatr 16:613-620, 2015

43. Verbeek RJ, Heep A, Maurits NM, Cremer R, Hoving EW, Brouwer OF, et al: Fetal endoscopic myelomeningocele closure preserves segmental neurological function. Dev Med Child Neurol 54:15-22, 2012

44. Wellons JC III, Holubkov R, Browd SR, Riva-Cambrin J, Whitehead W, Kestle J, et al: The assessment of bulging fontanel and splitting of sutures in premature infants: an interrater reliability study by the Hydrocephalus Clinical Research Network. J Neurosurg Pediatr 11:12-14, 2013

45. Wellons JC III, Shannon CN, Holubkov R, Riva-Cambrin J, Kulkarni AV, Limbrick DD Jr, et al: Shunting outcomes in posthemorrhagic hydrocephalus: results of a Hydrocephalus Clinical Research Network prospective cohort study. J Neurosurg Pediatr 20:19-29, 2017

46. Williams LJ, Rasmussen SA, Flores A, Kirby RS, Edmonds LD: Decline in the prevalence of spina bifida and anencephaly by race/ethnicity: 1995-2002. Pediatrics 116:580-586, 2005

\section{Disclosures}

The authors report no conflict of interest concerning the materials or methods used in this study or the findings specified in this paper.

\section{Author Contributions}

Conception and design: both authors. Acquisition of data: both authors. Analysis and interpretation of data: both authors. Drafting the article: both authors. Critically revising the article: both authors. Reviewed submitted version of manuscript: both authors. Approved the final version of the manuscript on behalf of both authors: Dewan. Administrative/technical/material support: both authors. Study supervision: both authors.

\section{Correspondence}

Michael C. Dewan: Vanderbilt University, Nashville, TN. michael. dewan@vumc.org. 